$\mathrm{VF}+$ and VF- patients $(\mathrm{p}=0.001)$. This result is further stressed in untreated T- subjects $(p<0.0001)$. Treatment, any medication $(T+)$, and drug therapy in particular, significantly counteract the difference between VF+ and VF- within groups (Table 1) and between groups with $T B L \beta$ values comparable to untreated VF- patients $(p=0.319)$ and statistically higher than untreated $V F+(p=0.014)$.

Table 1 Lacunarity of trabecular bone microarchitecture, TBL $\beta$,

can assess osteoporosis fracture risk and treatment efficacy

\begin{tabular}{|c|c|c|c|c|}
\hline \multirow[b]{2}{*}{ Patients } & \multirow[b]{2}{*}{$\begin{array}{c}\text { n VF-NF+ } \\
(\%)\end{array}$} & \multicolumn{2}{|c|}{ TBL $\beta$} & \multirow[b]{2}{*}{$\mathrm{p}$} \\
\hline & & VF- & $\mathrm{VF}+$ & \\
\hline Overall & $191 / 88(100)$ & $66 \pm 51$ & $46 \pm 42$ & 0.001 \\
\hline T- & $121 / 35(55.9)$ & $67 \pm 51$ & $36 \pm 29$ & 0.001 \\
\hline $\mathrm{T}+$, any medication & $70 / 53(44.1)$ & $65 \pm 52$ & $52 \pm 48$ & 0.091 \\
\hline VitD/Ca supplements * & $25 / 19(35.8)$ & $56 \pm 49$ & $36 \pm 24$ & 0.051 \\
\hline Drug therapy ${ }^{*}$ & $45 / 34(64.2)$ & $70 \pm 54$ & $62 \pm 56$ & 0.276 \\
\hline Bisphosphonates ${ }^{* *}$ & $43 / 27(88.6)$ & $70 \pm 55$ & $60 \pm 54$ & 0.225 \\
\hline
\end{tabular}

VF: prevalent vertebral fractures: $T$ - without treatment; $T+$ with treatment; * $\%$ within $T+$ patients: $* *$ within drug therapy group; $p$ : statistical significance from one-tail ttest

Conclusions: These promising results stress the usefulness of the method as a diagnostic tool in the assessment of osteoporotic fracture risk and suggest a potential role of $\mathrm{TBL} \beta$ as a marker of treatment efficacy. More intriguing results are expected from prospective LOTO data.

References:

[1] Zaia et al. IEEE Trans Inf Technol Biomed 2006; 10:484.

[2] Zaia et al. Osteoporos Int 2016; submitted.

[3] Zaia. World J Orthop 2015; 6:221.

Disclosure of Interest: None declared

DOI: 10.1136/annrheumdis-2017-eular.2719

\section{FRI0528 SUCCESSFUL IMPLEMENTATION OF A PHARMACIST-LED FRACTURE LIAISON SERVICE AT A US VETERAN AFFAIRS (VA) HOSPITAL}

B. Buehring ${ }^{1,2,3}$, T. Holobyn $^{3}$, J. Kotek ${ }^{4}$, B. Glynn-Servedio ${ }^{5}$, S. Wright ${ }^{6}$, K. Hansen ${ }^{1,3}$, A. Bridges ${ }^{1,3}$. ${ }^{1}$ William S. Middleton Memorial Veterans Hospital, Madison, United States; ${ }^{2}$ Rheumazentrum Ruhrgebiet, Herne, Germany;

${ }^{3}$ Department of Medicine, University of Wisconsin-Madison, Madison;

${ }^{4}$ Milwaukee VA Medical Center, Milwaukee; ${ }^{5}$ Durham VA Medical Center, Durham; ${ }^{6}$ VA Great Lakes Health Care System, Westchester, United States

Background: Worldwide, an osteoporosis (OP) care gap exists for individuals with a fragility fracture (FF). Published data shows that US veterans are no exception. To address the OP care gap, fracture liaison services (FLS) are being implemented with the goal to prevent additional FF.

Objectives: Here we report the patient outcomes after initiating a FLS at a US Veterans Affairs (VA) hospital.

Methods: We identified veterans with a pelvic, hip and/or femur shaft fracture by querying a central database. Veterans with traumatic fractures, active $O P$ medication, recent dual-energy X-ray absorptiometry (DXA) and/or hospice status were excluded. The remaining veterans were contacted via letter and the responsible primary health care team was sent a template letter with OP management recommendations via the electronic medical record. Recommendations included DXA, laboratory evaluation, and pharmacologic and non-pharmacologic interventions. In most cases, trained clinical pharmacists serving as FLS coordinators performed all tasks with an expert physician available for questions. Presented data are based on a review 4 months after recommendations were sent.

Results: The initial query revealed 149 veterans with pelvic, femoral, and/or hip fractures without a recent DXA and/or active OP therapy. Of those, 32 ( 31 males, 1 female) patients suffered a FF and were included in the FLS intervention. Our review showed that $59 \%$ of these had a DXA scan, $35 \%$ had their calcium/vitamin D intake reviewed, and $40 \%$ had started OP therapy or were referred to an OP specialist. When the primary care team's clinical pharmacist instead of the primary care provider implemented the FLS recommendations (10/32), 100\% of the recommendations were addressed. Furthermore, $70 \%$ of patients had a bisphosphonate ordered, whereas it was $9 \%$ when no pharmacist was involved $(\mathrm{p}=0.0004)$

Conclusions: Our study suggests that a pharmacist-led FLS improves post-FF care in US veterans. We found a high percentage of OP care goals met when patients interacted with clinical pharmacists. This observation might be due to the fact that most pharmacists had dedicated training in OP management and their interaction with the patient focused on their FF. In summary, our data suggests that clinical pharmacists trained in OP management can very effectively implement a FLS intervention.

Disclosure of Interest: None declared

DOI: 10.1136/annrheumdis-2017-eular.2793

\section{FRI0529 ANALYSIS OF THE EVOLUTION OF CORTICAL AND TRABECULAR BONE COMPARTMENTS IN THE PROXIMAL FEMUR AFTER SPINAL CORD INJURY BY 3D-DXA}

L. Gifre $^{1,2}$, L. Humbert ${ }^{3}$, A. Muxi ${ }^{4}$, L. del Rio ${ }^{5}$, J. Vidal ${ }^{6}$, E. Portell ${ }^{6}$, A. Monegal ${ }^{1}$, N. Guañabens ${ }^{1}$, P. Peris ${ }^{1}$. ${ }^{1}$ Rheumatology, Hospital Clínic of Barcelona, Barcelona; ${ }^{2}$ Rheumatology, Hospital Universitari Germans Trias Pujol, Badalona; ${ }^{3}$ Galgo Medical; ${ }^{4}$ Nuclear Medicine, Hospital Clínic of Barcelona; ${ }^{5}$ CETIR, Barcelona; ${ }^{6}$ Spinal Cord Unit, Guttmann Neurorehabilitation Institute, Badalona, Spain

Background: Spinal cord injury (SCI) is associated with a marked increase in bone loss and risk of osteoporosis development short-term after injury. 3D-DXA is a new imaging analysis providing volumetric measurements of the cortical and trabecular bone from DXA scans.

Objectives: The aim of this study was to assess the evolution of $3 D$ femoral shape, trabecular macrostructure and cortical bone from DXA scans in patients with recent $\mathrm{SCI}$ followed over 12 months.

Methods: 16 males with recent $\mathrm{SCl}$ ( $<3$ months since injury) were included Clinical assessment, bone mineral density (BMD) measurements and 3D-DXA evaluation at proximal femur (analyzing the integral, trabecular and cortical volumetric BMD [vBMD] and cortical thickness) were performed at baseline and at 6 and 12 months of follow-up.

Results: vBMD measured by 3D-DXA significantly decreased at integral, trabecular and cortical compartments at 6 months $\left(-31.1 \mathrm{mg} / \mathrm{cm}^{3},-8.8 \%\right.$, $\mathrm{p}<0.001 ;-25.4 \mathrm{mg} / \mathrm{cm}^{3},-11.6 \%, \mathrm{p}=0.001$; and $\left.-20.4 \mathrm{mg} / \mathrm{cm}^{3},-2.4 \%, \mathrm{p}=0.004\right)$, with a further decrease at 12 months, resulting in an overall decrease of -58.9 $\mathrm{mg} / \mathrm{cm}^{3}(-16.6 \%, \mathrm{p}<0.001),-47.9 \mathrm{mg} / \mathrm{cm}^{3}(-21.9 \%, \mathrm{p}<0.001)$ and $-42.4 \mathrm{mg} / \mathrm{cm}^{3}$ $(-5 \%, p<0.001)$, respectively. Cortical thickness also decreased at 6 and 12 months $(-8 \%, p<0.001$; and $-11.4 \%, p<0.001)$, with the maximal decrease being observed during the first 6 months. The mean BMD loss by DXA at femoral neck and total femur were $-17.7 \%(p<0.001)$ and $-21.1 \%(p<0.001)$, at 12 -months, respectively. Integral $\mathrm{vBMD}$ values at baseline were positively correlated with total femur BMD $(r=0.874, p<0.001)$, however no correlation was observed in the changes in these values at 12 -months.

Conclusions: 3D-DXA shows the differentiation of the marked bone loss that occurs at both proximal femoral compartments (cortical and trabecular) short-term after SCI. The present data suggest that 3D-DXA could be a useful complementary assessment tool in $\mathrm{SCI}$ patients.

Disclosure of Interest: None declared

DOI: 10.1136/annrheumdis-2017-eular.3103

\section{FRI0530 EFECTIVENESS OF AN ORTHOGERIATRIC FRACTURE} LIAISON SERVICE COMPARED WITH STANDARD CARE

A. Naranjo $^{1}$, S. Fernández Conde ${ }^{2}$, S. Ojeda ${ }^{1}$, S. Rodríguez ${ }^{3}$, L. Torres Hernández $^{4}$, I. Bernardos ${ }^{1}$, I. Rodríguez ${ }^{3}$, V. Kraev ${ }^{3}$, C. Hernández Carballo ${ }^{4}$, P. Laynez ${ }^{4}$. ${ }^{1}$ Rheumatology, Hospital Univ. Gran Canaria Dr. Negrin, Las Palmas de Gran Canaria; ${ }^{2}$ Internam Medicine, Hospital Universitario NS Candelaria, Santa Cruz de Tenerife; ${ }^{3}$ Geriatrics, Hospital Univ. Gran Canaria Dr. Negrin, Las Palmas de Gran Canaria; 4 Internal Medicine, Hospital Universitario NS Candelaria, Santa Cruz de Tenerife, Spain

Background: Our fracture liaison service (FLS) for outpatients has reported to maintain $73 \%$ of the patients on antiresorptive 2 years after the fracture. For hip fracture we are concerned about the low capture rate $(27 \%)$.

Objectives: To analyze the efectiveness of a FLS for inpatients with hip fracture compared with standard care.

Methods: Observational study carried out in two hospitals, one with a FLS (Hospital Negrin) and the other one with standard orthogeriatric care (Hospital Candelaria). The reference population $>65$ y from H.Negrin and H.Candelaria are 63,382 and 63,249 inhabitants respectively.

We included patient $>65$ y with fragility hip fracture ocurred between 1th March 2016 and 31th July 2016. Severe dementia, non-fragility fractures and those patients who died during hospital admittance were excluded. All patients underwent hemogram and biochemistry. The densitometry was not performed on any patient. The only difference between hospitals was a dedicated nurse from the FLS H.Negrin who visited inpatients twice a week, interviewed patients, gave education and applied a treatment protocol to be started by Primary Care.

Data recorded were: age, sex, previous fractures and previous treatment for osteoporosis, including calcium, vitamin D, bisphosphonates, denosumab and teriparatide. We also collected the treatment that was included in the discharge report and treatment six month later (checking the electronic prescription).

Results: We included 185 patients (105 from Hospital Candelaria and 80 from Hospital Negrin), mean age 82 y (Table). The percentage of patients receiving a bisphosphonate or equivalent before hospital admittance was similar in both hospitals. However, the percentage after discharge rose by $91 \%$ in the hospital with FLS and remain $8 \%$ in the hospital with standard care. After six months, $75 \%$ of patients from FLS and $15 \%$ of patients with standard care had a treatment. Conclusions: The implementation of an orthogeriatric FLS lead to an increase in treatment for osteoporosis compared with standard care and similar to our outpatient FLS model. The ideal approach to secondary fracture prevention is a FLS model of care in an integrated health care network, overseen by a nurse coordinator. 